\title{
Aquí no se habla Spanglish: The Issue of Language in US Hispanic Media
}

\author{
Ana Carolina Walczuk Beltrão \\ Warsaw University, Poland \\ abeltrao@wp.pl
}

\begin{abstract}
A strong and still growing ethnic community in the United States, Hispanic Americans, with a common language but culturally diverse, have for years constituted a challenge for the media. How to communicate with them? With the development of Spanish-language print, broadcast, and cable outlets within American territory, communication became easier. Some of these media, however, have for years denied Hispanic Americans one of their most genuine forms of expression: namely, the use of Spanglish, a language generated by immigrants. The two major Hispanic American television networks in particular have adopted the policy of vetoing the use of Spanglish. The issue may be very upsetting for many Hispanic Americans who consume information on a daily basis. It becomes even more upsetting, then, when the same media also self-appoint themselves as "representatives of the Hispanic American population". If the hybrid language is one of the few elements that indeed unite and represent the Hispanic group in America, shouldn't these media rethink their practices? This is exactly what this article intends to answer, taking the case of Hispanic American television, from an initial description of Hispanics in America, to a closer analysis of the major media outlets available in the country.
\end{abstract}




\section{1. "Latinos" or "Hispanics": a nation within North America}

According to the 2000 US Census, Hispanics account for $12.5 \%(35,305,818)$ of the total American population $(281,421,906)$, surpassing the previous largest minority group, that of African Americans (33,947,837). Between 1990 and 2000, Hispanics achieved the highest growth rate in America (57.9\%). Nowadays, it is believed that the Hispanic American population has surpassed 41,000,000 (according to a Time magazine report of August 2005 ${ }^{1}$ ).

Once "Hispanic Americans" were just another group of immigrants in North America, but nowadays they are present in all 50 states of the federation and largely concentrated in key states like California, Texas, New York, and Florida, where entire districts are under their influence. To have an idea of what that influence means, by the year 2000 "The city of Los Angeles earned the title of the third largest Spanishspeaking city in the world (...)” (Valle \& Mandel, 2003: 3). Also, the 2000 US Census reports revealed that Hispanics are the majority population of California (32\% of state residents), Texas (also 32\%), and New Mexico (42\%). It is a population composed mostly of Mexicans (58\% of all Hispanics), Puerto Ricans and Cubans, but also encompassing people from other Latin American countries.

The term "Hispanic" was first used in the 1980 Census to designate the group of "Spanish-Hispanic origin": people "whose ancestry is based in a Spanish-speaking country and who identify with Hispanic cultures" (Jandt, 1995: 314, after Guernica, 1982), regardless of race. Fox (1996: 12) still recalls that the term is commonly used “(...) to mean nothing more than 'people of Spanish-speaking heritage,' regarding it as politically and racially neutral”. Representatives of the group, however, tend not to accept this "Hispanic" identity created by the American government to designate the Spanish-speaking population. The term "Hispanic" has been accused of rejecting the culture and history of indigenous and colonized people in favor of European roots (Dávila, 2001: 15). A term preferred by the population is "Latino", which refers to "Spanish-speaking individuals who came from, or whose ancestors came from, anywhere in Latin America” (Jandt, 1995: 315, after Guernica, 1982) and is more connected with the social struggles and activism of the 60s and 70s (Dávila, 2001: 15).

Both terms are commonly used in North America to address a mass of people who share similar heritage and cultural values by means of a common language, even though representatives of the group itself do not see themselves as such. Actually, many accept those terms, but claim that people from different Latin American countries have different ways of living. Ethnicity, though, is not simply a matter of nationality, but of distinguishing features such as language or accent, physical attributes, customs, and religion, as Jandt states (1995: 12). Also, each of these groups followed a different pattern of migration to the US: while Cubans, Nicaraguans and Salvadorans mostly looked for political asylum, a great number of Latin Americans have moved for economical reasons. Part of the Mexican population, on the other hand, has simply remained in their lands annexed by Americans in the beginning of the $19^{\text {th }}$ century. And, still, the Hispanic American population is constituted by racial multiplicity, so that using one term to designate them all as an ethnic group can only be mistaken: they are 
predominantly of American Indian ancestry, but also White, Black, and Asian, due to the history of colonization (Parillo, 1994: 406).

North Americans became more interested in categorizing this ethnic group as it started to gain visibility in the 1960s and 70s. Then, followed the rapid growth of Hispanic immigration in the 1980s, the so-called década perdida ("lost decade"), in Latin America, whose economic crisis and political unrest pushed many of its inhabitants northwards. In the 90s, immigration continued to rise and the population growth could be attributed to other aspects, like the high birth rate among Hispanic families in US territory. But immigration numbers have always been the most striking: according to Parillo (1994: 407), 44\% of all legal US immigrants in the last century came from Spanish-speaking countries, besides millions of Latinos who illegally cross the 2,000-mile boarder with Mexico or try to reach the North American coast.

They come from different nations with different cultural nuances, but in North America are united by their sharing of the Spanish language: "Despite some differences among them, Latinos constitute a distinctive linguistic and cultural group (...)”. (Suro, 1999: 6). And their importance in shaping the future of the country in economic, social and political terms is undeniable.

\section{The melting pot $X$ multiculturalism: Latinos and the issue of assimilation}

Until recently, the North American "melting pot" was still a common image to describe how immigrants in North America would assimilate the culture of the new land. According to this view, different immigrant cultures do exist in the country, but are not perceived individually once they have all blended together to make up a single culture, that of North America, which, as a consequence, must be fully assimilated. Undoubtedly, the "melting pot" idea was accepted when applied to European immigrants going to North America until the first half of the $20^{\text {th }}$ century. However, by the second half of the century, the "melting pot" had become, according to authors Wilson II and Gutiérrez (1995: 7), rather a "huge pot of stew". That meant many immigrants, non-Europeans especially, would no longer assimilate towards a single North American culture, but, instead, they would retain some of the features of their own cultures, while acquiring others from the new land and creating new identities for themselves. From this point onwards, North America has become a "multicultural society”.

As far as the Hispanic American immigration is concerned, many aspects have contributed to the North American "stew". First, immigration from Latin America sharply increased in the second half of the $20^{\text {th }}$ century, making Spanish-speaking communities more visible than ever. Second, as Huntington (2004) claims, sustained influx promoted the "cultural consolidation" of Hispanic cultures. Also, civil unrest in the 60s led ethnic groups to call out for recognition and celebration of their cultural heritages, and regional concentration also played its part: Mexicans in California, Cubans in Miami, Dominicans and Puerto Ricans in New York - the more concentrated immigrants become, the slower and less complete is their assimilation. Lastly, 
geographical proximity to Latin America and new technological devices, according to Suro (1999: 124), have kept Hispanics constantly in contact with their homelands.

Still, language was a factor for retaining Hispanic identities and cultures in North America. Almost all of the $1^{\text {st }}$ generation immigrants and many Latinos born in the US choose to speak Spanish at home - a total of 28,101,052 US inhabitants 5 years old or over, according to the 2000 US Census. Use of the Spanish language is an attempt to keep alive their own traditions, as Parillo says (1994: 445).

It is not probable that Hispanic Americans will ever reject Spanish in favor of English: with the rapid growth of the Latino community, Spanish-language speakers are less motivated to adopt English. And, usually, even second- or third-generation Hispanic parents emphasize the need for their children to be fluent in Spanish, an attitude that contrasts with that of other ethnic groups (Huntington, 2004). More than 90\% of Hispanic adults speak Spanish at home. Hispanic Americans in the future will probably become more assimilated, but still be bilingual in their majority.

Finally, it is also worth mentioning that, especially in the barrios, a new, specific Hispanic American culture is being created. Therefore, the issue of non-assimilation in some cases is not only a matter of retaining Hispanic cultures, but also generating new forms of cultural expression, among which a new form of language, Spanglish, appears: "These are barrios where Latinos invent new kinds of music and new identities and where a new generation of Americans is trying to define itself while living in a constant state of transition". (Suro, 1999: 125). It is not the purpose of this article to describe in detail the system and usage of Spanglish as a language; it is important, though, to call attention to its wide use among Latinos in the US, some of whom are not anymore acquainted with a "pure" version of Spanish from their countries of origin.

\section{Latinos and the media}

At this point, let us consider that for most of the time the term "mainstream media" in the US is a synonym of "white-dominant media". One of the main roles of these media was to sustain the North American society as a homogeneous one. Then, confronted with a multicultural conjuncture in the 1960-70s, media executives realized it was time to change some of their policies-either of exclusion, indifference towards minorities, or stereotyping, so as to address tiers of the population that had not yet been properly catered to. Not only social forces contributed to this, but also pressure from marketing agencies and advertisers (the main source of income of every media outlet), eager to profit from the growing numbers.

Within a multicultural society, some see the reinforcement of diverse cultural identities as a problem, but many others see it as an opportunity to grow. In this case, two strategies would emerge: firstly, the existing media would try to address ethnic groups within their own content-such is the case, for example, of radio stations that include Spanish-language music in their programming, or newspapers that offer supplements dedicated to Latin America in Spanish, or TV channels that promote new ethnic characters in sitcoms and soap operas. Secondly, new media would be created 
specifically to address such groups-TV channels, radio stations, newspapers and magazines directed at Hispanic Americans, or Spanish-language versions of mainstream outlets. This way, Spanish-language media developed to cater to a vast population in the United States as a forum for Hispanic ideas and interests, a channel for their leaders, and the advocate voice of their people, as many claim to be.

The first printed news to circulate in the American continent, back in the $16^{\text {th }}$ century, were published in New Spain (as the Spanish colonies were then called) and featured texts both in Spanish and native languages (Wilson II \& Gutiérrez, 1995: 174175). In fact, this early Hispanic press largely influenced the development of the North American press as well. And, together with the first North American mass circulation medium-the New York Sun, in 1833, the first half of the $19^{\text {th }}$ century witnessed the blossoming of Hispanic newspapers in North America. The first of them was El Misisipi, founded in 1808 in New Orleans, which in fact was not intended to give voice to Latinos living in North America, but a publication with news mostly from Europe especially concerning the Napoleonic occupation of Spain and wars-and bilingual local advertising-in Spanish and English. Despite being published by Anglos, Wilson II and Gutiérrez (1995: 181) claim that El Misisipi anticipated many trends to be later found in Hispanic American publications: bilingualism, "foreignness" of content and commercial interest, among others.

Other Latino publications were launched in the following years and assumed a more challenging role than that of El Misisipi. Some, for example, offered an alternative source of information to Mexicans living in the areas of dispute between Mexico and the United States in the first half of the $19^{\text {th }}$ century. Also, these newspapers played an important role in preserving the Hispanic language and cultural identity, becoming “(...) the principal publisher of literature including poetry, literary prose, and even serialized novels (...)”, as Kanellos (1994: 239) writes. Generally, in the end of the $19^{\text {th }}$ century, with the Hispanic flow of immigrants and the political unrest in Latin American countries, the number of Spanish-language newspapers began to increase (ibid: p. 241). Nevertheless, these could not survive for different reasons, as Fox (1996: 41) states: "They (the Hispanic communities) were not densely enough populated (in most of the Southwest), were not stable enough (in the case of the exiles of the Northeast), or were not receiving enough new Spanish speakers to replace those who died or were assimilated into the English language culture (...)”.

Later, in the beginning of the $20^{\text {th }}$ century, new Hispanic media have emerged. It was a period of record immigration of Latinos to North America, especially because of the Mexican Revolution of 1910 and the US occupation of former Spanish colonies in the Caribbean after the Spanish-American War. And, according to Kanellos (1994: 242), not only low-class workers made up this mass of immigrants, but also upper-class professionals and intellectuals, causing different publications to be launched with an eye on social classes and nationalities. Still, some of the periodicals attempted to promote ethnic unity among Latinos and fight racial and cultural prejudice (Kanellos, 1994: 243). Lastly, Hispanic Americans could listen to the first radio programs broadcast in Spanish in the mid-1920s (Subervi-Vélez, 1994: 327-328). 
However, the Great Depression of the 1930s caused many of the Hispanic media to disappear. Only later in the 1960s were Hispanics in North America to experience the flourishing of Spanish-language media again, some of which were part of Civil Rights campaigns, demanding recognition and political power for ethnic minorities ${ }^{2}$, and others purely commercial.

Fox (1996: 41) recalls that until the end of the 1960s there were three major Hispanic media markets: Cubans concentrated in South Florida, Puerto Ricans in New York, and Mexicans in California, having “(...) little contact with one another, separated by geography, dialect, and radically different social and political concerns”. Then, two factors contributed to create an integrated Hispanic American media industry: record immigration flows coinciding with a reasonably mature Hispanic market, and the growth of nationwide Spanish-language television, which helped create and maintain a single identity for Latinos across the country, influencing other media towards an integrated market as well (ibid: 41-42). As early as in 1976, a major Spanish-language broadcaster, SIN (Spanish International Network), began distributing programming via domestic satellite to its affiliates. These technical developments strongly supported the idea of a unified, nationwide Hispanic market (Dávila, 2001: 62). Compared to other minorities in the US territory, only Latinos could count with such a nationwide forum an advantage commonly attributed to their sharing of a single language (Fox, 1996: 41).

By that time, big players in the Latino-oriented media turned out to be mostly corporations of Latin American or Anglo origins, not representatives of national Hispanic subgroups anymore. Dávila (2001: 51, after Whisler \& Nuiry, 1998, and Broadcasting and Cable, 1998) writes that, from the 1970s to 1998, the number of publications for Hispanics increased by 219 percent, and from 1990 to 1998, the number of Hispanic radio stations have doubled, reaching 594 outlets, while minority media ownership decreased to 3 percent. As Fox (1996: 54) also states, in the past “(...) Hispanic media were owned and run by people from the same community that they served. Today, however, both television networks, four of the five daily newspapers, and most of the radio stations are owned by public and private US companies”. It is a complex represented by “(...) an array of television, newspapers, radio, and book and magazine publishers, a \$450-million-a-year industry reaching every Spanish-speaking neighborhood in the United States”. (ibid: p.40). Major US media corporations, such as Times-Mirror, New York Times, NBC, CNN, HBO, and MTV, have launched publications, programs or channels oriented to the national Spanish-speaking audience in the 1990s (Wilson II \& Gutiérrez, 1995: 246).

The fact that today's Spanish-language media does not belong to Hispanic Americans is not necessarily prejudicial, though. Actually, the Hispanic media have gained so much respect and credibility in the recent years, that politicians as well as advertisers cannot ignore their importance anymore. Fox recalls that in the 1970s it was hardly possible for Hispanic American media to get into a mayoral conference, whereas in the 1992 elections both Bill Clinton and George Bush agreed on exclusive interviews for the Hispanic press (Fox, 1996: 57). This means Spanish-language media have conquered not only respect, but, at least to some degree, influence. In many ways, these 
media can mobilize the Hispanic American community-encouraging people to vote and to cooperate with the census, collecting donations for victims of disasters, carrying out campaigs for better public services, warning against frauds to which immigrants may fall victims, and generating the image of Latinos as active participants in public life.

As Subervi-Vélez (1999) notes, Hispanic-American television is "among the most pervasive of ethnic-oriented media” in the United States. Univisión and Telemundo, the two major Latino-oriented networks based in Miami and fully broadcast in Spanish, were officially created in 1987 and nowadays reach over 90\% of Hispanic American households with entertainment and informational programs. In metropolitan areas like Los Angeles and Miami, during certain hours of the day, these stations have higher ratings than their English-language counterparts (Fox, 1996:42). Yet, the content of their programming grids does not vary considerably: both television networks have relied mostly on importing cheap Latin American programming into the US market, rather than producing their own shows at a higher cost. Telenovelas and variety shows were bought from Mexico, Venezuela, Peru and other Hispanic countries. In the beginning, especially, Spanish-language networks seemed to be the venue through which US-based Latinos would "consume and experience Latin America from within the US context”, as Dávila (2001:24) puts it. Very little of their programming was produced locally.

Also, Hispanic American media outlets have always imported talents from Latin America, instead of looking for US-born Latinos to fill especially creative posts. The number of US-produced television programs has increased since the mid 1980s, but have heavily relied on a specific artistic pool of Latin American "authentic" Spanishspeakers (Dávila, 2001: 28). When inquired about the number of posts occupied by Hispanics, Spanish-language media executives eagerly say that Latinos make up more than half of their board of directors, and that their workforce is overwhelmingly Hispanic; they do not mention, however, that most of the artistic and high-ranking posts are occupied by Hispanics who had been "imported" from Latin America. Dávila (2001) associates this phenomenon of an "ethnic labor division” partly with the perfect language skills that recently arrived Latin Americans display:

A direct result of the Spanish-language-centered infrastructure of the US Hispanic marketing industry is an ethnic division of labor whereby the Latin American corporate intellectuals from middle- and upper-class backgrounds rather than US-born Latinas (sic) ${ }^{3}$ generally dominate the creation and dissemination of 'Hispanic' images in this country. (Dávila, 2001:34).

(...) the Hispanic market industry's Latin American connections have led to the dominance in the US media market of what the industry calls "Spanish-dominant" Latinas (sic), who have relocated to the United States as adults, often to pursue advanced studies, or who have had previous experience in the advertising and marketing industries in some of the major Latin American markets (...) and who have kept their so-called grammatically correct Spanish-language skills. (ibid). 


\section{Language matters}

In 2004, a Nielsen Media Research study commissioned by Univisión found that the majority of Hispanic Americans can watch television in both Spanish and English, but they overwhelmingly spend more time watching Spanish-language TV for language preference and also because they consider Spanish to be an important part of their identity, a connection to family, roots, and community (in "Univisión Unveils Conclusive Consumer Research on the Who, Why and How of Spanish-Language TV", Business Wire, 2004). In fact, most of the Latino-oriented media are available only in Spanish, but some are bilingual, and others present their content exclusively in English. Of course, people working for the Latino-oriented media should be bilingual and well acquainted with Hispanic American culture and issues. Very little is heard, however, on the use of Spanglish by these media. Fox (1996: 65) writes that Spanish-language media in North America, among other relevant roles, help “(...) develop the Hispanic nation's content-wide dialect, peculiarly adapted to its North American environment”. Therefore, Spanglish, widely used by the Latino population, should also find its place among the Hispanic American media. Taking consideration of the two biggest Hispanic American television networks, Univisión and Telemundo, one sees, however, that such is not the case.

The emphasis on Spanish by media executives and the willingness of Latinos to keep the language alive in a foreign land is understandable, once the Hispanic nation builds itself within the larger North American community. As Fox (1996: 39) recalls, the maintenance of Spanish represents, for the people, "the vehicle for achieving collective power" and visibility in the new land, and, for the media, a whole new market to be explored. There is, after all, the "need for generic constructions with which to emphasize unity and mutual recognition among the 'Hispanic nation's' countries and cultures” (Dávila, 2001: 91); hence, the common language propagated by the media, and especially by television, creates a linguistic bond among groups as diverse as Mexicans, Cubans, Puerto Ricans and others, newcomers or not.

Therefore, the majority of Hispanic American media preach the use of a "pure", correct Spanish. This is something appreciated by Latinos willing to maintain their language alive, and take pride in it. Dávila (2001: 192-195) affirms that Latinos interviewed by her wanted to find this "pure" Spanish - that is, Spanish untainted by English - on Spanish-language media. For example, the majority of Latinos who consume these media agreed, when asked, that Spanglish must be ruled out on television, the appropriateness of Spanish being "(...) a central component of their Latino/Hispanic identity and a reason why they tuned in to the Spanish channels". According to the expectations of many Latinos, these media should assume an educational role regarding the use of language. As one interviewee confirmed to Dávila (ibid): "I watch the novelas to brush up on my Spanish. 'Cause we Latinos speak Spanish and should teach it to our children”.

In the case of Hispanic American television, the selective use of bilingualism is accepted in some of Telemundo's entertainment programs, but in Univisión it is completely ruled out, “(...) using only the so-called correct and generic Spanish, in their 
abstention from Spanglish, and, most of all, in their appropriation of the role of guardians of and instructors in the language within the larger Hispanic community”. (Dávila, 2001: 165-166). Notably, on Univisión's Cristina talk show, the most successful among its kind, the hostess demands that their guests speak only Spanish; phrases in Spanglish or "broken English" are eventually covered with a "beep” sound (ibid: p.168). Moreover, most of the foreign professionals who fly to North America with profitable contracts as TV hosts are not expected to get acquainted with the language and ordinary life of a Hispanic immigrant, or a Latino born in the barrio; these professionals are rather hired to perform in the same way they used to back in their home countries - which, according to Dávila (ibid: p.159), does not really change the pattern of importing cultural products.

Yet, for many Hispanic Americans it is natural to speak Spanglish - what is more, some of them were born into it. For this group, the Spanish propagated by the media will never correspond to the one spoken on the streets, at home and among friends. The untainted Spanish chosen by the two major television networks, therefore, does not reflect the real life of their audience. This becomes clear especially when Latinos are brought on air: "That business of Spanglish (...) I think that's what we struggle against most. But it's impossible”. - said to author Fox (1996: 60) a journalist covering New York City for Univisión, complaining that people interviewed on the streets would always mix the two languages. On the other hand, the Spanish found in such media, the so-called "generic" Spanish, will never be the language spoken anywhere back in Latin America. It is a language that does not exist elsewhere, a hybrid form of different modes of Latin American Spanish, with no local accents or lexical differences, created so to be understood by all Spanish speakers living in North America.

US Hispanics have actually become a distinct nation within North America with its own culture and language to be catered to. Nonetheless, Hispanic American television networks keep carrying on the policy of "true Hispanidad" and unspotted Spanish, so as to foster the idea of a homogeneous ethnic unity and, consequently, conquer a stable market through language. Indeed, it is much easier for these media to deal with what is "known", that is, with a language whose rules and lexicon are available at any time, than to adventure in the use of Spanglish, which is constantly being created by the people as a reflection of their experiences in the new land.

The "true Spanish/true Hispanidad" policy, which lead Hispanic American networks to focus on imported content and talent, finally impoverishes their programming grids but maintains profits high, to the detriment of local production and coverage, as well as local talents. And, mostly because of the "foreignness" of Spanishlanguage television, some media executives and researchers share the opinion that a great mass of Hispanics may never fully assimilate the North American culture: “(...) they are constantly undergoing a process of cultural refueling (...)”, said the vicepresident of a Hispanic marketing agency (in Dávila, 2001: 79). Somehow, it is not in these media's interest to have Latinos assimilated the mainstream culture, but rather "accommodated" within the American dynamics of race and ethnicity - the survival of Spanish-language media depending mostly on the existence of a non-assimilated, 
Spanish-speaking audience. This, on the other hand, clearly contradicts the media's self-appointed role as a "resource to help Latinos navigate their way in the US" (Lowry, 2004).

\section{Conclusion}

The Hispanic American media actually face the impossibility of a fair ethnic representation: Hispanics as a homogeneous, culturally defined market is an idea as inaccurate as the term "Hispanics" itself, for all the differences that exist among Latin American nations and people who originally come from them. What is more, the association of these media with particular nationalities and/or locations, such as the Cubans and their influence in Miami outlets, prevents them from being perceived as truly pan-Hispanic products (Dávila, 2001: 162). It seems, therefore, that any development towards a more representative system should focus on Hispanics' lives in North America, what is common to all of them, and not their origins. On the other hand, the transnationalization of the media in terms of content and the emphasis on foreignborn Latinos bring negative consequences to Hispanic Americans as consumers of such media-out of which non-assimilation is a vicious example. This way, the media is constantly recreating and legitimizing models of Hispanic ethnicity that do not always correspond to their audience's reality. This practice should change, so that Hispanic American media may be experienced not as a medium of marginalization (Dávila, 2001: 182). Hence, it seems imperative for Hispanic American media to finally acknowledge the existence of a new culture of Latinos living in the US, a new sort of life, and typical manifestations of it.

Such is the case of language - why not accept the use of Spanglish in certain circumstances, if not at all times? That would not lead to the ruling out of all forms of Hispanidad from Latin America and the use of "pure" Spanish, but rather portray Latinos within the new North American reality they experience, instead of trying to reproduce life from somewhere else. After all, if pure language and culture were the most relevant for Latinos, they could have it straight from Latin America through imported publications, internet and satellite broadcast. Also, the acceptance of a genuine US Latino culture would reject Spanish-language media's dependence on the Latin American industry and market.

This obviously should require the insertion of Spanish-language media in a more US-generated process of content and talent development, emphasizing who and what is "local" (here, meaning who and what is found in the country) rather than "foreign" (that is, from Latin America). Eliminating the emphasis on "foreignness" should also fight the problem of portraying Latinos as aliens and a threat to the North American society. Very often the media inaccurately represent the population, showing Hispanic Americans as a group of recent Spanish-speaking immigrants, while actually the group is much more complex. A more accurate, local portrayal could, indeed, promote a better understanding of what it means to be a Latino in North America - both within the minority group and among other members of society. 
Nonetheless, people appreciate the existence of Spanish-language media in North America. Despite all criticism, these media have been perceived as the channel through which Latinos have conquered visibility and political power in the US. As Dávila (2001: 191-192) states, the growth of Spanish-language media is for many an "indicative of Latino achievement and enfranchisement" and something to be proud of. As Veciana-Suarez (1990: 17) states, Hispanic American media are the ones who "(...) point out injustices, expose prejudices, open recalcitrant doors, salute triumphs”. Still according to Veciana-Suarez (ibid), this is especially true of minority newspapers and broadcast outlets, for “(...) their readers and listeners often have no other recourse”.

Is it legitimate, then, to call Hispanic American media "the voice of Latinos"? Clearly not, if they do not even speak the same language. However, the improvement of such media would be profitable for both audience and industry, and must be expected for the near future.

\section{Notes}

1. As published on August $16^{\text {th }}, 2005$ by Diario TV Latina, "Los hispanos están 'reconfigurando' a Estados Unidos”, retrieved on the same date from http://www.tvlatina.info/.

2. In the case of Hispanic Americans, the Civil Rights movement translated itself into many forms of social resistance and self-affirmation, like the Chicano movement of Mexican Americans in the Southwest, and the Puerto Rican Young Lord's Party in New York. Slowly, the number of Latinos increased not only in demographic terms everywhere in the US, but also in political and economic power. Moreover, it was in the 1960s that the Hispanic American population took form as an ethnic identity, for both matters of self-identification and governmental ethnic designation. At this time, the term "Hispanic" gradually surpassed national origins to represent a single group in the country.

3. Term used by the author instead of "Latinos".

\section{References}

Dávila, Arlene (2001): Latinos Inc.: The Marketing and Making of a People. Los Angeles: University of California Press.

Fox, Geoffrey (1996): Hispanic Nation: Culture, Politics, and the Constructing of Identity. Tucson: The University of Arizona Press.

Halter, Marilyn (2000): Shopping for Identity: The Marketing of Ethnicity. New York: Random House.

Huntington, Samuel (2004): “The Hispanic challenge”. Foreign Policy, Mar. 1, 2004. Retrieved Jan. 25, 2005. Available: [www.highbeam.com].

Jandt, Fred E. (1995): Intercultural Communication: An Introduction. Thousand Oaklands, CA: SAGE Publications.

Kanellos, Nicolás (1994): “A Socio-Historic Study of Hispanic Newspapers in the United States”. In F. Padilla, ed., Handbook of Hispanic Cultures in the United States: Sociology. Houston: Arte Público Press, 239-256.

Lowry, Brian. (2004): “TV still at a loss for words with Latinos”. Variety Magazine, April 26, 2004. Retrieved Jan. 25, 2005. Available: [www.highbeam.com]. 
Parillo, Vincent N. (1994): Strangers to these Shores: Race and Ethnic Relations in the United States. New York: Macmillan Publishing Company.

Subervi-Vélez, Frederico (1994): "Mass Communication and Hispanics". In F. Padilla, ed., Handbook of Hispanic Cultures in the United States: Sociology. Houston: Arte Público Press, 239-256.

Suro, Robert (1999): Strangers Among Us - Latino Lives in a Changing America. New York: Vintage Books.

Univisión Unveils Conclusive Consumer Research on the Who, Why and How of SpanishLanguage TV. (March 3, 2004). Business Wire. Retrieved Jan. 25, 2005 Available: [www.highbeam.com].

Valle, Francisco J. and Mandel, J. (2003): How to Win the Hispanic Gold Rush: Critical, Cultural, Demographic, Marketing, and Motivational Factors. New York: iUniverse.

Veciana-Suárez, Ana (1990): Hispanic Media: Impact and Influence. Washington, D.C.: The Media Institute.

Wilson II, Clint C. and Gutiérrez, F. (1995): Race, Multiculturalism, and the Media: From Mass to Class Communication. Thousand Oaklands: SAGE. 